\title{
Enterprise Financial Risk Identification and Information Security Management and Control in Big Data Environment
}

\author{
Ran Wei ${ }^{1,2}$ and Sheng Yao ${ }^{1}{ }^{1}$ \\ ${ }^{1}$ School of Management, China University of Mining and Technology, Xuzhou 221116, Jiangsu, China \\ ${ }^{2}$ School of Accounting, Shandong Women's University, Jinan 250300, Shandong, China \\ Correspondence should be addressed to Sheng Yao; yaosheng@cumt.edu.cn
}

Received 25 June 2021; Revised 22 July 2021; Accepted 6 August 2021; Published 7 September 2021

Academic Editor: Sang-Bing Tsai

Copyright (c) 2021 Ran Wei and Sheng Yao. This is an open access article distributed under the Creative Commons Attribution License, which permits unrestricted use, distribution, and reproduction in any medium, provided the original work is properly cited.

\begin{abstract}
With the deepening of business informatization, all kinds of business application data are rapidly gathering, which promotes enterprises to enter the era of big data. Enterprises begin to build the concept of big data, deepen the understanding of big data, extract potential data value, and improve the operation ability of enterprises and information systems. At the same time, big data brings internal control information to the system, which is becoming more and more challenging, so enterprises pay more and more attention to the security of the information system. This paper aims to introduce the enterprise financial risk identification and information security management and control under the big data environment and master the enterprise financial risk identification method so that the enterprise can adapt to the needs of the times competition faster and better. This paper introduces the method of identifying financial risk in the background of big data by classifying the methods of financial risk identification and designing the factor model. Through the experimental investigation of the company's financial asset rate, the enterprise financial risk situation is displayed, and the enterprise can improve the internal management to control the financial risk within a certain range. The experimental results show that from 2016 to 2020, the internal control and asset rate of the enterprise affect the financial risk of the enterprise, $82 \%$ of the operators only have a reasonable debt structure and sufficient solvency, the operator can operate in a safe state and then maintain a low financial risk, and the operator should also take measures to prevent the occurrence of risk in advance and realize the business goal of maximizing benefits.
\end{abstract}

\section{Introduction}

Big data is a hot topic in the theoretical and practical fields. Although many scholars have analyzed the risk of internal information system control from different angles, the research on internal control risk of the information system in large enterprises is not rare. This paper expounds the importance of studying the risk of the internal information system in large enterprises in the big data environment. From the perspective of management, the internal control process of the information system is divided into five stages: supervision and guidance, organization and planning, construction and implementation, service and support, and evaluation and analysis. According to the characteristics of different stages, the risk assessment system is established, and the risk of the large enterprise information system is evaluated by establishing a model.

Big data age is coming. According to the service objects of big data, big data application fields were mainly divided into four categories: government big data, enterprise big data, Internet big data, and personal big data. Among them, Internet big data developed rapidly and achieved good results, while government, enterprise, and individual were able to make good achievements, big data still has a preliminary development stage, which is the direction that needs more efforts. In the Internet plus era, any enterprise can become a big data resource enterprise. Enterprises in different industries need to have the concept of big data to meet the wave of big data and make full use of the opportunities brought by big data to optimize their own business and of 
vital importance. According to the integration into their own business, the advantages and benefits brought by big data to enterprises will be brought into play.

Financial risk is related to the wrong financing of enterprises, unreasonable financial structure, poor management of capital assets, and unscientific investment methods, which may cause the company to lose its solvency, which leads to the decrease in expected income of investors. Rathore $\mathrm{M}$ believed that the number of people using Internet and network services is increasing, and that the Internet generates a large amount of data from zeta bytes to $\mathrm{Pb}$ at a very high speed every day. We see more security threats on the web, on the website, and on the corporate network. The proposed system consists of fourlayer IDS architecture, which consists of capture layer, filter layer and load balance layer, processing layer or Hadoop layer, and decision layer. However, at present, it lacks specific data proof [1]. Wu C believed that in the big data environment, enterprises must absorb big data knowledge and private knowledge through multiple knowledge transfer to maintain competitive advantage. The best time of knowledge transfer is one of the most important aspects to improve the efficiency of knowledge transfer. Through the analysis of the complex characteristics of knowledge transfer in big data environment, we can divide many kinds of knowledge transfer into two types. One is to transfer all kinds of knowledge at the same time, and the other is to transfer multiple knowledge at different time points. Considering the influencing factors such as knowledge type, knowledge structure, knowledge absorption capacity, knowledge update rate, discount rate, market share, profit contribution of each knowledge, transfer cost, product life cycle, and time optimization maximize the total discounted expected profit of the enterprise, but its development is relatively vague [2]. Zhu Zhiping believed that the impact of corporate governance hedging can be identified in different ways. The substantial improvement of governance standards has effectively reduced foreign exchange exposure and increased more hedging of foreign exchange derivatives, and the economic scale of this effect is very large. The GMM estimation of dynamic panel confirms the significant positive correlation between governance quality and hedging. However, it lacks specific proof at present [3].

The innovation of this paper is to study the financial risk identification of enterprises in big data environment by qualitative analysis. Through the principle experiment of the factor model method and investigation and analysis of the situation of financial risk of the company, it is helpful to us to understand the role of corporate governance and effectively prevent the financial risk of the company by constructing a reasonable corporate governance structure.

\section{Identification Method of Financial Risk}

2.1. Meaning and Characteristics of Financial Risk. There is no unified theory about the definition of financial risk. According to the different perspectives, there are several views as follows. From the perspective of financing, financial risk can be defined $[4,5]$. In financing activities, the actual income of the enterprise in the future is uncertain, so it will lead to the occurrence of financial risk. The enterprise needs to repay the principal and interest due to the debt, which leads to the financial risk of the enterprise $[6,7]$. More debt, the greater the risk. Without liabilities, there will be no financial risk. The definition of financial risk from the perspective of capital structure is 8-9. The risk of the interest and dividend that cannot be paid or difficult to pay due to the imbalance of capital structure is defined as financial risk $[8,9]$. This view is similar to the definition of financing angle, but it is more prominent to improve the financial risk of enterprises by allocating their own funds and debt funds, combining with the domestic and foreign financial risk research, and summarizing five characteristics of financial risk.

\subsection{Financial Risk Analysis Method}

2.2.1. Qualitative Analysis. Experts and scholars analyze and judge the existing or potential financial risks of enterprises based on previous experience, historical information, and literature data and predict the trend of financial risks so as to provide basis for preventing and controlling financial risks $[10,11]$.

2.2.2. Quantitative Analysis. The paper analyzes the financial statement data and historical information of the enterprise, then judges the current situation of the financial risk of the enterprise, and then develops an analysis method for the financial risk prevention measures $[12,13]$.

\subsubsection{Investigation and Experimental Research Method.} Through single financial index and its amendment, the financial risk of enterprises is predicted and developed. The selected financial indicators are obtained through a large number of data analysis, with a strong scientific $[14,15]$. We explore the contrast of enterprise finance through specific experiments to detect the current situation of financial risk of enterprises $[16,17]$.

2.3. Types of Financial Risks. Financial risk refers to the possibility that the actual income is lower than expected income due to the influence of various uncontrolled factors during the production and operation of the company. There are many forms of risk finance due to the uncertainty of financial risk. The classification of financial assets according to different risk standards is different. According to the form of financial risk, it can be divided into static financial risk and dynamic financial risk finance. According to the capital flow process of the company, it can be divided into financing risk, investment risk, refinancing risk, and income sharing risk [18].

\section{Financial Risk Model Experiment}

3.1. Principle of Factor Model Method. When using the factor model method to evaluate the overall benefits of enterprises, reliable data should be collected according to the design 
needs of the model. In theory, we can build the following comprehensive evaluation model of corporate governance:

$$
H_{j}=\sum_{i} \mathrm{bF}_{i j}
$$

Among them, $H_{j}$ represents the enterprise $j$. The overall performance of our company $F_{i j}$ by $j$ standardized value of company index $B$ is $I$, which means that after linear transformation and elimination of a small part of information, the original multidimensional variables are replaced by a small number of principal components, and then these principal components are rotated to obtain an economically interpretable conversion probability of complex factors.

$$
H_{i}=R_{i} \sum_{i}^{f} R_{i}
$$

Among them, $R_{i}$ is the third factor corresponding to the coefficient, $H_{j}$ is the characteristic element of the characteristic root, and the standard value of each main factor and the original index value correspond to the number of weight factors and characteristic roots:

$$
Q=h_{1} Q_{1}+h_{2} Q_{2}+\cdots+h_{n} Q_{n} W_{i} .
$$

3.2. Calculation of Leverage Method. Due to the limitation of objective conditions, it is impossible to obtain internal data directly, so the income before interest and tax is obtained by the sum of financial expenses and operating profit in the profit distribution statement of the listed company's annual report:

$$
S=\left(\mathrm{EBT}_{1}-\mathrm{EBT}_{2}\right) \times S_{1} .
$$

When calculating the financial leverage, according to the definition, the following formula is selected:

$$
S=\left(E P S_{1}-E P S_{2}\right) \times \frac{E B T_{1}}{E P S_{1}} \times\left(E B T_{1}-E B T_{2}\right) .
$$

\subsection{Mathematics Comprehensive Fuzzy Evaluation Method.} The fuzzy and general evaluation method refers to the application of fuzzy mathematics principle to solve the problems that are difficult to quantify in qualitative evaluation [19]. The evaluation results are obtained. In this paper, the fuzzy mathematics theory is used to evaluate the financial risk factors of $M$ and $A$ systematically [20]. The basic steps of establishing fuzzy relation $s$ are as follows:

$$
S=\left[s_{n 1}, s_{n 2}, \ldots, s_{n 5}\right] .
$$

When $H$ is the relative weight value of $f_{i}$, the result of two-level comprehensive fuzzy evaluation is as follows:

$$
B=H, H_{j}=\left(a_{1}, \ldots, a_{n}\right) .
$$

\section{Identification and Analysis of Company Profile and Financial Risk}

4.1. Identification of Single Financial Indicator. The analysis of the financial status of the industry uses a single financial indicator, which compares the actual financial indicators of the company with the single financial indicator of the industry, analyzes the company's overall financial status, and initially identifies the company's financial risks. The results are shown in Table 1.

It can be seen from Table 1 that from 2016 to 2020, the company's rapid correlation degree is low, which is lower than the industry's low value in 2016, the ability of rapid asset realization to repay current liabilities is weak, and the debt repayment pressure is obvious. In the past five years, the asset-liability ratio has been around $70 \%$, which has not reached the average value of the industry or even lower than the lower value of the industry. The debt level is significantly higher than the average value of the industry. As a result, the company faces great debt risk, and its comprehensive solvency guarantee ability is seriously insufficient. The ability of EBIT to cover debt interest is weaker than that of most enterprises, and its long-term solvency is not as good as that of most enterprises. Generally speaking, company has weak solvency and high debt ratio in recent years. It is at the downstream level of the industry and has high financing risk, as shown in Figure 1.

The turnover rate of accounts receivable decreased year by year, from higher than the industry value to lower than the industry perfect value thus affecting the company's solvency. The operating capacity of the company is basically above the average level of the industry, and it still maintains a good operating level and good medium- and long-term financing capacity. It should be noted in recent years that almost all operating capacity indicators have a downward trend, which has a direct impact on the company's solvency and needs to be controlled in time.

4.2. Financial Risk Information Module. Financial risk identification is the basis of financial risk evaluation and control. Only when enterprises fully understand the current situation of financial risks, can they formulate reasonable risk prevention measures according to the characteristics and causes of risks. The common identification methods of agricultural listed enterprises include univariate analysis, multiple linear analysis, and comprehensive index method, but they are more prominent. Through the allocation of selfowned funds and debt funds, in order to improve the financial risks of enterprises, combined with the financial risk research at home and abroad, the sum of financial risks of enterprises has five characteristics, as shown in Figure 2.

Only the enterprise has a reasonable debt structure and sufficient solvency, can operate in a safe state, and maintain a low financial risk. The best financing channels and diversified sources of funds are the important achievements of the early financing ability, and enterprises can create a strong risk response ability and maintenance ability and develop rapidly, as shown in Table 2. 
TABLE 1: Solvency analysis.

\begin{tabular}{|c|c|c|c|c|c|}
\hline Solvency index (time) & 2016 & 2017 & 2018 & 2019 & 2020 \\
\hline Quick ratio (\%) & 40.45 & 50.65 & 60.45 & 45.67 & 42.34 \\
\hline Asset-liability ratio (\%) & 80.67 & 34.76 & 67.45 & 65.46 & 76.32 \\
\hline Cash current debt ratio & 2.22 & 1.34 & 1.61 & 1.40 & 1.22 \\
\hline Rate ratio & 2.34 & 4.56 & 3.34 & 4.42 & 4.32 \\
\hline
\end{tabular}

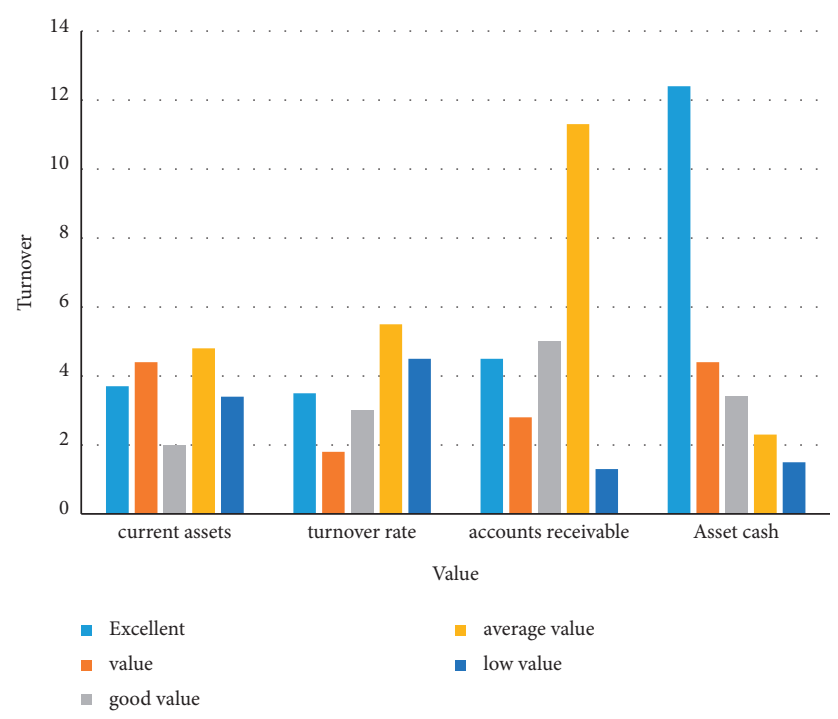

FIGURE 1: Standard value of the company's operating capability evaluation.

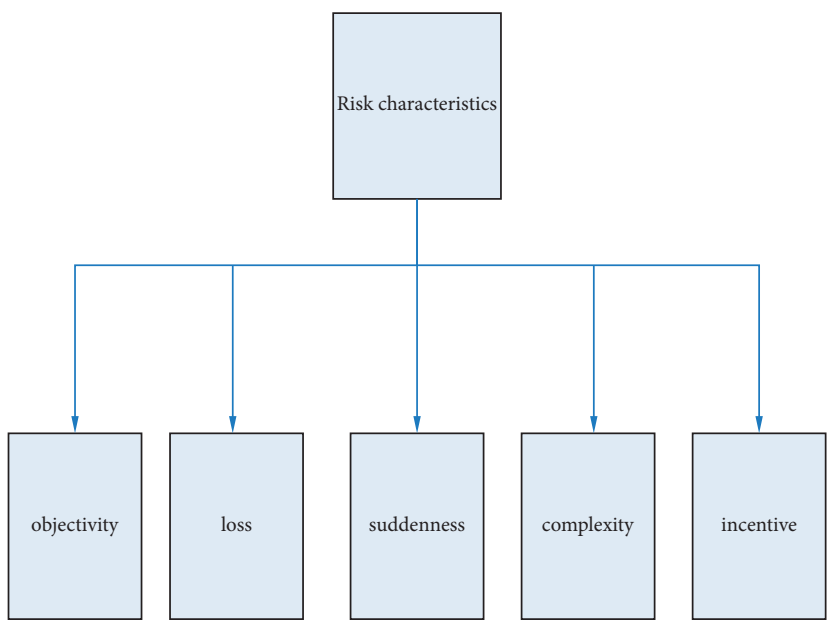

Figure 2: Phrase translation model training process.

4.3. Information Security Control. The openness and sharing of the network are easy to threaten the network security and information system [21]. Network information plays an important role in enterprise work, but it also faces security risks. In order to build the enterprise information system on modern information platform, based on the application of the information system in network and scientific security theory, a comprehensive experiment of high security, low risk, high efficiency, applicability, and reliability is carried out. The results are shown in Figure 3.

As shown in Figure 3, by analyzing the current situation of information network security, the company's needs, and security objectives and using the latest advanced information network security management concepts and security technologies, the original information network security system has been transformed, optimized, modernized, and transformed. The original information network security 
TABle 2: Debt structure and related indicators.

\begin{tabular}{lccc}
\hline Financial indicators & 2018 & 2019 & 2020 \\
\hline Quick ratio & 0.66 & 0.43 & 0.33 \\
Short debt to equity ratio (\%) & 83.70 & 67.67 & 78.76 \\
Interest cover (\%) & 6.45 & 4.55 & 7.65 \\
Current ratio & 0.76 & 0.45 & 0.34 \\
Long-term debt ratio (\%) & 45.65 & 43.65 & 76.65 \\
Short debt ratio (\%) & 32.66 & 98.34 & 55.65 \\
\hline
\end{tabular}

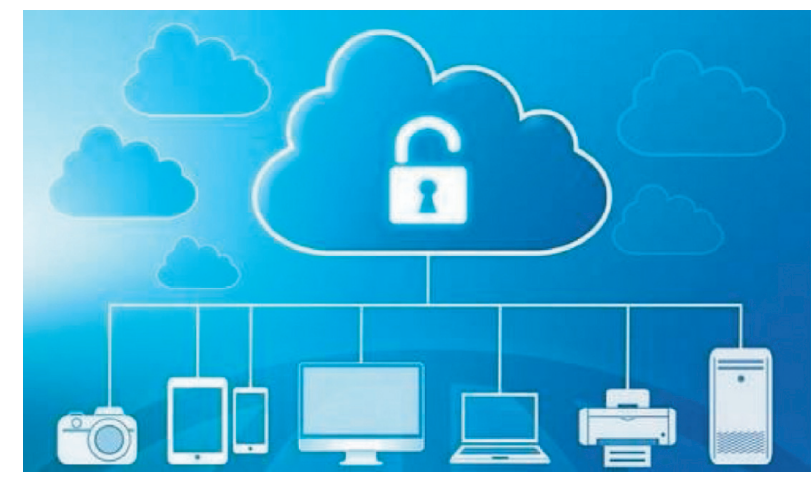

FIGURE 3: Information security control (http://alturl.com/vz6s9).

system is designed as an information network management and control system suitable for the current centralized and unified corporate governance and security system to improve the security level of the company's information network and minimize the risk [22].

\section{Conclusions}

With the deepening of China's economic system reform, the company has become a self-management, self-financing, self-sufficiency, and self-development operator and the company must bear the risk independently. Through the experimental factor model and other detailed data, we draw the conclusion: for enterprises, defining financial risk, establishing and improving risk management mechanism, and strengthening risk prevention will become the important content of the current economic system reform but also the internal requirements of enterprises improve economic efficiency and support their own development. It is important to correctly understand risks, correctly analyze various risks faced by enterprises, and reasonably prevent and control risks. Strengthening financial risk prevention has become one of the goals of current financial reform, which is not only the inevitable requirement of the market economy but also the call for modern entrepreneurs.

\section{Data Availability}

No data were used to support this study.

\section{Conflicts of Interest}

The authors declare that there are no conflicts of interest.

\section{Acknowledgments}

This work was supported by National Natural Science Foundation of China under Grant 71572189.

\section{References}

[1] M. M. Rathore, A. Ahmad, and A. Paul, "Real time intrusion detection system for ultra-high-speed big data environments," The Journal of Supercomputing, vol. 72, no. 9, pp. 3489-3510, 2016.

[2] C. Wu, E. Zapevalova, Y. Chen et al., "Time optimization of multiple knowledge transfers in the big data environment," Computers, Materials and Continua, vol. 54, no. 3, pp. 269285, 2018.

[3] Z. Zhu, "Public security management in the big data environment $\%$ public security management in the big data environment," Journal of Shanghai Public Security College (Public Security Theory and Practice), pp. 90-96, 2016.

[4] S. Yang, M. Yang, S. Wang et al., "Adaptive immune genetic algorithm for weapon system portfolio optimization in military big data environment," Cluster Computing, vol. 19, no. 3, pp. 1-14, 2016.

[5] C. Wen, "Ghost identification based on single-pixel imaging in big data environment," Optics Express, vol. 25, no. 14, pp. 16509-16516, 2017.

[6] L. Bo, L. Wang, and C. Wang, "Mathematical model of precision education and several problems in big data environment," Mathematical Modeling and Its Applications, vol. 6, no. 4, pp. 32-40, 2017.

[7] X. Chen and N. Metawa, "Enterprise financial management information system based on cloud computing in big data environment," Journal of Intelligent and Fuzzy Systems, vol. 39, no. 1, pp. 1-10, 2020.

[8] N. Wen, "Risk identification and response in financial and accounting treatment of security company," Value Engineering, vol. 035, no. 19, pp. 66-68, 2016. 
[9] J. D. Chi and X. Su, "Product market threats and the value of corporate cash holdings," Financial Management, vol. 45, no. 3, pp. 705-735, 2016.

[10] M. Sar, "DODD-Frank and the spoofing prohibition in commodities markets," Fordham Journal of Corporate and Financial Law, vol. 22, no. 3, pp. 383-416, 2017.

[11] M. Kovacova, A. P. Balcerzak, and M. Moszynski, "Management of financial risks in Slovak enterprises using regression analysis," Oeconomia Copernicana, vol. 9, no. 1, pp. 105-121, 2018.

[12] L. Karthik, M. Subramanyam, A. Shrivastava et al., "Prediction of wilful defaults: an empirical study from Indian corporate loans," International Journal of Intelligent Technologies and Applied Statistics, vol. 11, no. 1, pp. 15-41, 2018.

[13] C. B. Pellegrini, M. Meoli, L. Pellegrini et al., "Systemic risk determinants in the European banking industry during financial crises, 2006-2012," Rivista Internazionale di Scienze Sociali, vol. 126, no. 2, pp. 109-122, 2018.

[14] F. Natalia and A. S. Maria, "Detecting financial statements fraud: the evidence from Russia," Journal of Corporate Finance Research, vol. 11, no. 2, pp. 32-45, 2017.

[15] T. M. Brunner-Kirchmair and M. Wiener, "Knowledge is power-conceptualizing collaborative financial risk assessment," The Journal of Risk Finance, vol. 20, no. 3, pp. 226-248, 2019.

[16] V. Mendelová and T. Bieliková, "Diagnosing of the corporate financial health using DEA: an application to companies in the Slovak republic," Politicka Ekonomie, vol. 65, no. 1, pp. 26-44, 2017.

[17] B. D. Beal and M. Astakhova, "Management and income inequality: a review and conceptual framework," Journal of Business Ethics, vol. 142, no. 1, pp. 1-23, 2017.

[18] E. J. Lusk, M. Halperin, and B. D. Zhang, "The balanced scorecard: suggestions for rebalancing," Problems and Perspectives in Management, vol. 4, no. 2, pp. 100-114, 2017.

[19] L. Yin, W. Pan, J. Kuang, and M. Zhuang, “Application of bootstrap-DEA with fuzzy computing in performance evaluation of forklift leasing supplier," IEEE Access, vol. 8, 2019.

[20] S. B. Tsai, M. F. Chien, Y Xue et al., "Using the fuzzy dematel to determine environmental performance: a case of printed circuit board industry in Taiwan," Plos One, vol. 10, no. 6, 2015.

[21] D. Chen, P. Wawrzynski, and Z. Lv, "Cyber security in smart cities: a review of deep learning-based applications and case studies," Sustainable Cities and Society, vol. 66, Article ID 102655, 2020.

[22] Y. Tang and M. Elhoseny, "Computer network security evaluation simulation model based on neural network," Journal of Intelligent and Fuzzy Systems, 2019. 